\title{
A Review on Progressive Collapse of Building Structures
}

\author{
Hao Wang*, Anqi Zhang, Yi Li and Weiming Yan \\ Beijing Key Laboratory of Earthquake Engineering and Structural Retrofit, Beijing University of Technology, Beijing \\ 100124, China
}

\begin{abstract}
Progressive collapse of building structures is generally triggered by a local failure due to accidental actions, followed by subsequent chain effect of the structures which may result in wide range failure or even collapse of the entire buildings. Since the " 911 " event, progressive collapse of building structures has been widely concerned by engineers and researchers. This paper assesses the current researches on this issue from experimental study, numerical simulation and theoretical analysis. Given the limitation of costs and difficulties of experimental tests, the experimental studies investigate the collapse mechanism, such as development of stress/strain and damage/failure of materials, mainly via the scaled down specimens of structural components and substructures. On the other hand, the collapse behavior of entire building structures is analyzed via the numerical methods, such as the finite element method and the discrete element method. Further, the collapse resistance demand and the robustness assessment for building structures are theoretically studied in depth in which the simplified theoretical models of the collapse-resisting demand and the collapse risk assessment are proposed respectively. At last, the design method to prevent progressive collapse for building structures is also discussed.
\end{abstract}

Keywords: Building structures, design method, experimental study, numerical simulation, progressive collapse, theoretical analysis.

\section{INTRODUCTION}

A progressive collapse of a building is initiated by an unexpected event that causes local damage and subsequently propagates throughout the structural system, leading to a final damage state in large-scale or entire collapse of the building [1]. A progressive collapse can be triggered by accident actions, including fire hazard, gas explosion, terrorist attack, vehicle collision, design and construction errors, and environmental corrosion. With the development of industrialization, the buildings with multi-function and high complication become more common of which the safety and stability are far more concerned. However, the current ultimate limit state design based on the structural reliability theory is commonly used for regular structures to ensure their safety. On the other hand, during the long-term use, the structure may suffer unexpected accidental actions, causing local damage or failure. Hence if the remaining structural system cannot absorb or contain the internal force variation caused by the initial failure, it will lead to a further damage even the collapse of whole structure, causing huge loss of life and property.

To end this, the international design guidelines and codes for building structures to prevent progressive collapse have

*Address correspondence to this author at the Beijing Key Laboratory of Earthquake Engineering and Structural Retrofit, The College of Architecture and Civil Engineering, Beijing University of Technology, Beijing 100124, China; Tel:(+86)13426060561; Fax: 010-67391649;

E-mail: wanghao528@emails.bjut.edu.cn been correspondingly edited and revised for three times following the three serious progressive collapse incidents. The first one is the collapse of the Ronan Point Tower in Canning Town, London in 1968 [2], as shown in Fig. (1). Shortly after the incident, the provisions for progressive collapse were consequently introduced into a number of codes and standards in British and Canada for the first time. The second happening is the collapse of the Alfred P. Murrah Federal Building in Oklahoma City in 1995 [3], as shown in Fig. (2). After that, the American standards

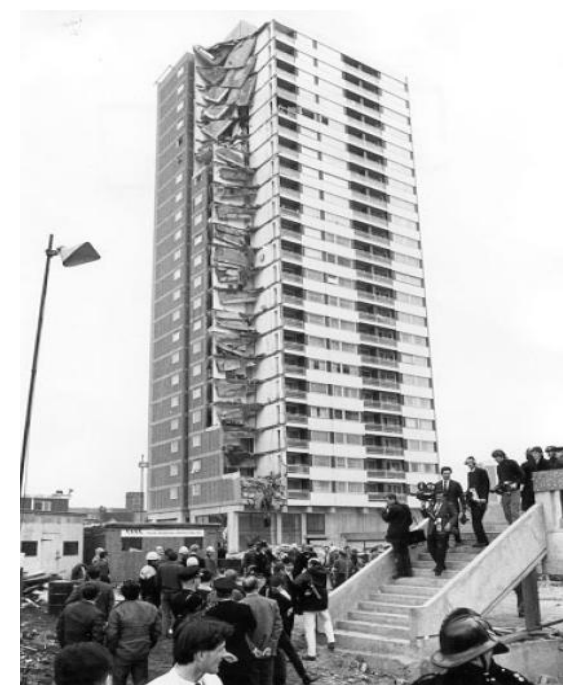

Fig. (1). The progressive collapse of Ronan Point Apartment [2]. 
enhanced the progressive collapse design provisions while several specific codes aiming at progressive collapse were established. The third issue is the collapse of the world trade center (twin tower) in USA in 2001 [4], as shown in Fig. (3). This issue acted as a catalyst during the revision of the progressive collapse provisions. In 2004, Crowder [5] summarized a series of major progressive collapses and the publishing date of related provisions and codes. Fig. (4). clearly showed the intertwining between them. In China, the provisions related to progressive collapse are presented in Code for Concrete Structure Design (GB50010-2010) [6] and Technical Specification for Concrete Structure of Tall Building (JGJ3-2010) [7]. Both of them only provide basic rules for the principles and requirements for progressive collapse design, while specific specification for buildings is still on the consultation stage.

The progressive collapse of building structures is a complicated mechanical behavior of entire structural systems under large deformation. However, limited researches have been conducted to investigate this issue at the last century due to the lack of the experimental technique and numerical simulation for entire structural systems under large deformation. In recent years, with the development of the experimental technique and numerical simulation, the progressive collapse of building structures is studied in depth and the exciting progresses have been reported. This paper summarizes the existing researches on the progressive collapse of building structures and especially focuses on its development in experimental study, numerical simulation and theoretical analysis, as shown in Fig. (5). Finally, the design method for building structures to prevent progressive collapse is discussed.

\section{EXPERIMENTAL STUDY}

Given the limitation of costs and difficulties of experimental tests, the experimental studies investigate the

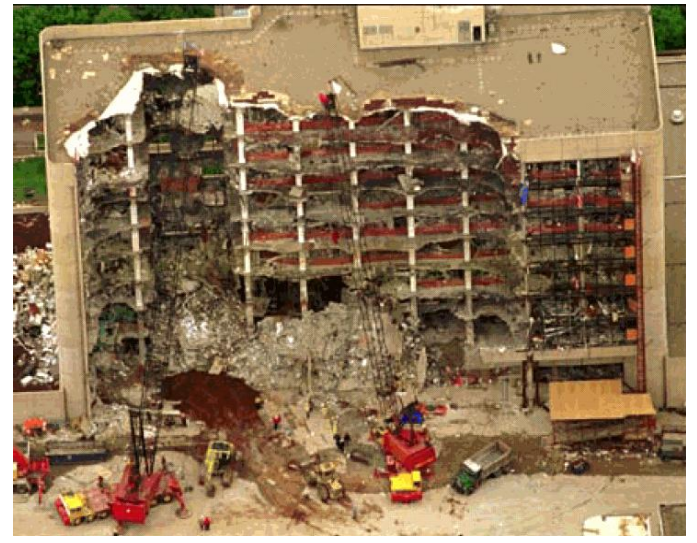

Fig. (2). The progressive collapse of Alfred P. Murrah Federal Building [3].

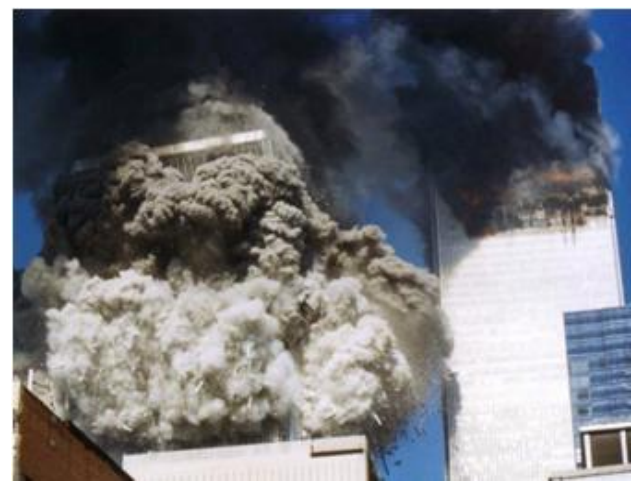

Fig. (3). The progressive collapse of WTC towers [4].

collapse mechanism, such as development of stress/strain and damage/failure of materials, mainly via the scaled down specimens of structural components and substructures. Besides, the progressive collapse experiments focus on the specimens under large deformation which is much larger

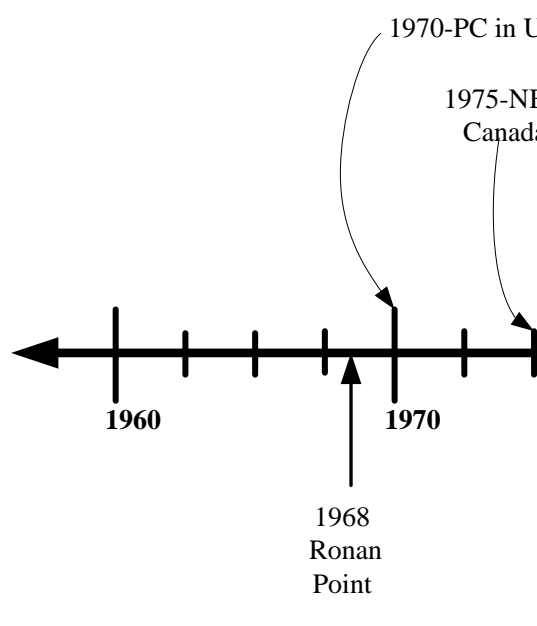

in UK Building Regulations

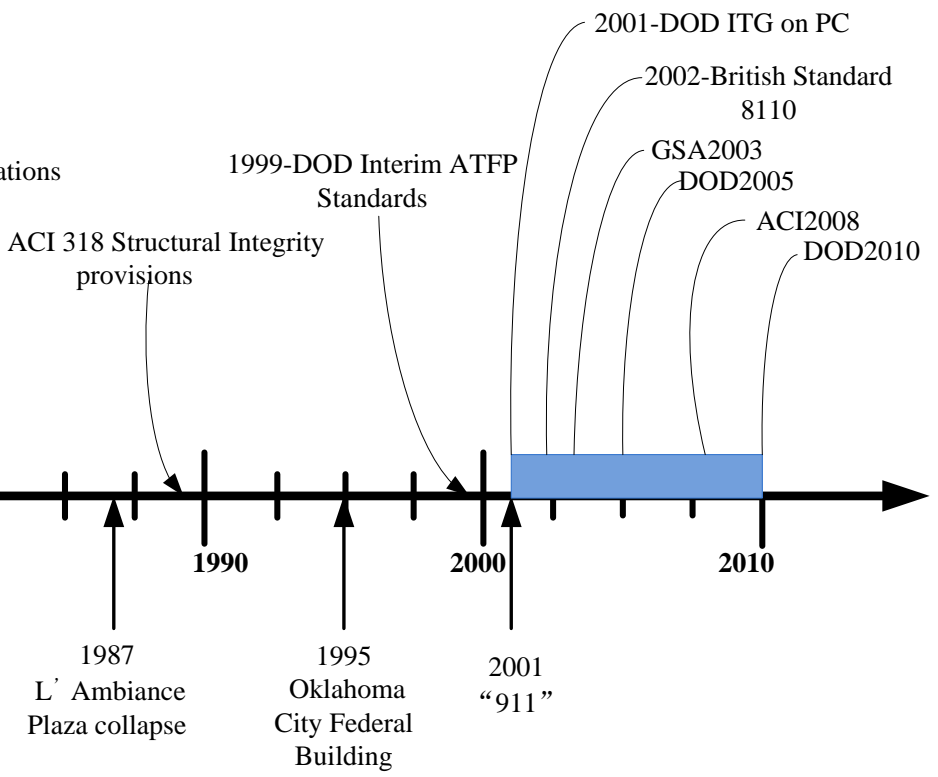

Fig. (4). Significant progressive collapse events and design code time [5]. 


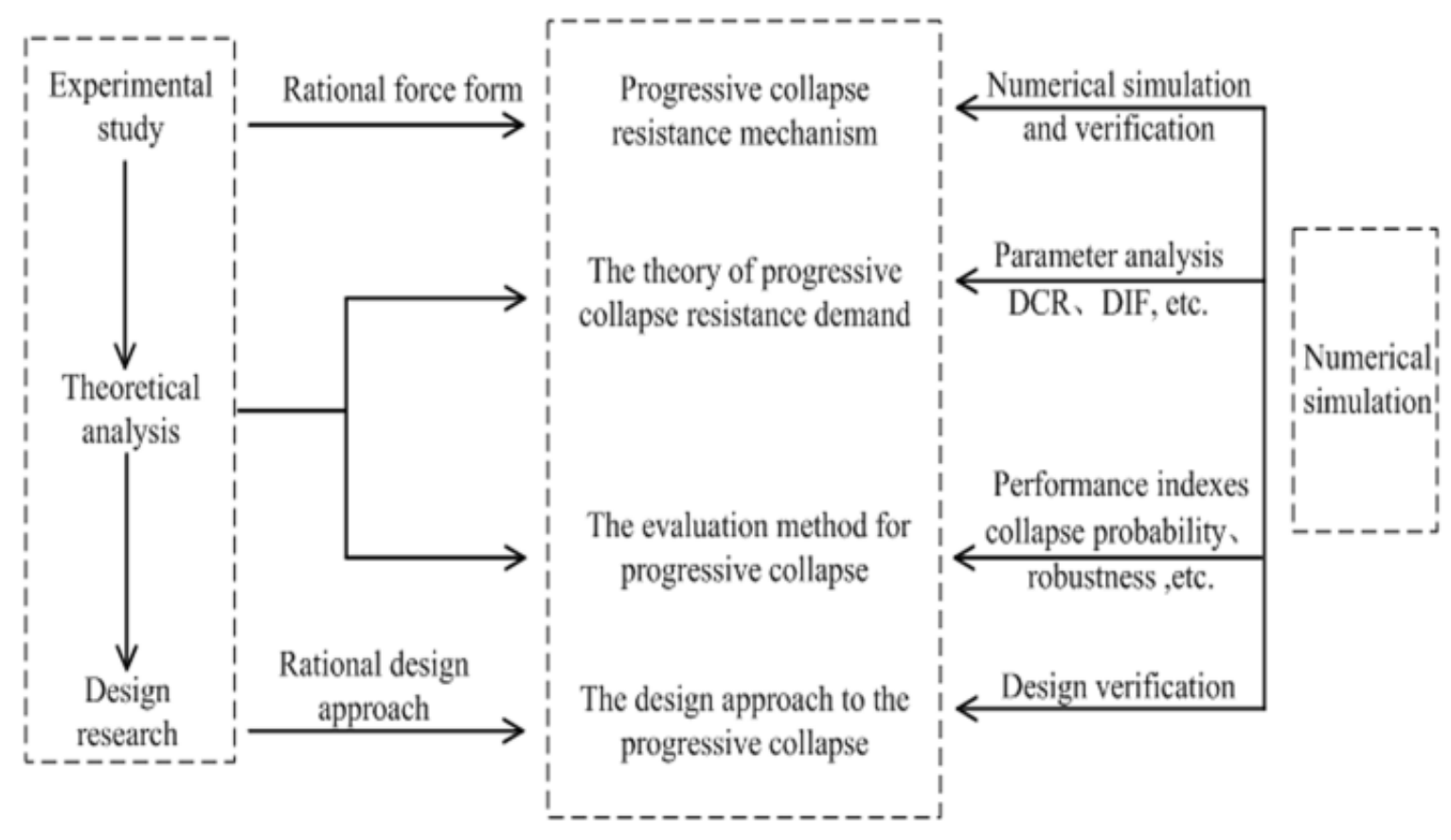

Fig. (5). The existing studies on progressive collapse.

than that in seismic studies. Therefore, the advanced experimental techniques are required to feasibly apply the collapse loads and measure the response of specimens. Two kinds of experiments are mainly applied, including the static experiment controlled by the displacement and the dynamic test by instantaneously removing supporting device, as shown in Fig. (6).

Abolhassan et al. [8] conducted a full-scale test on a single-floor steel structure in University of California, Berkeley. The result showed that the catenary effect originating from the precast steel cable in the slab can effectively prevent the building from progressive collapse. Sasani and Kropelnicki [9] tested a 3/8 scaled continuous beam in a concrete frame structure by instantaneously removing a vertical column, to investigate the catenary effect of the reinforcing steel bars at the top of the frame beam section. Kai and $\mathrm{Li}$ [10] from Nanyang Technological University conducted the progressive collapse experiments on the full-scale beam-column concrete structures with different reinforcement ratios and stirrup spacing. The results revealed that the load-displacement curve, the crack development and the mechanism of the collapse of these substructures. Then, 6 groups of $1 / 3$ scaled beam-column models were tested to study the dynamic collapse mechanism [11]. Results showed that the span length plays an important role in the progressive collapse resistance. Sadek et al. [12] did the full-scale tests on the two concrete frames and the two steel frames and studied the effect of the seismic design on the progressive collapse resistance of the frame and the damage and failure of the materials during the collapse process. Su [13] and Yi [14] carried out the progressive collapse tests of concrete frame beams to study the progressive collapse resistance capacity and mechanism of the beams. Yap and Li [15] tested the progressive collapse resistance performance of reinforced concrete beam-column joints. Mitchell and Cook [16] finished a series of collapse experiments on scaled RC slabs to analyze the overall collapse process of the slabs. The numerical model for the $\mathrm{RC}$ slabs under the ultimate collapse state is also presented. By analyzing the two-way slabs supported on the extremely stiff beams and the typical two-way slab structures, the contribution of the reinforcing steel bars at the joints to the progressive collapse resistance is discussed. Zineddin et al. [17] conducted the impact-loading experiments on three groups of RC slabs and discovered that the reinforcement ratio and the impact height can significantly affect the impact resistance of RC slabs. Zhang and Yi [18] tested the progressive collapse resistance of flat plates and analyzed the compressive membrane action and tension membrane action. Huang and $\mathrm{Gu}$ [19] conducted the progressive collapse experiment on a 3-storey frame with single span while numerical analyses were involved to model the specimen and to study its reliability. Yi and Xiao et al. [20] tested a scaled 4-span 3-storey RC frame to investigate the pressure arch and the catenary effect of RC frame beams and discussed the algorithms of the bearing capacities at two stages. Xiong et al. [21] conducted a pseudo static experiment on a spatial $\mathrm{RC}$ frame and found that the beam mechanism, comprehensive mechanism, and catenary mechanism successively occurred in longitudinal direction of the frame whilst only the beam mechanism existed in transverse direction. Lu and $\mathrm{Ye}$ et al. [22, 23] conducted a series of pseudo static experiments including a RC frame, two beamcolumn joints and four typical frame columns.

Experiments on wasted buildings destructed by site blasting can better show the progressive collapse resistance of real structural systems. Song and Sezen [24] tested the Ohio Student Union building which was located on the Ohio 


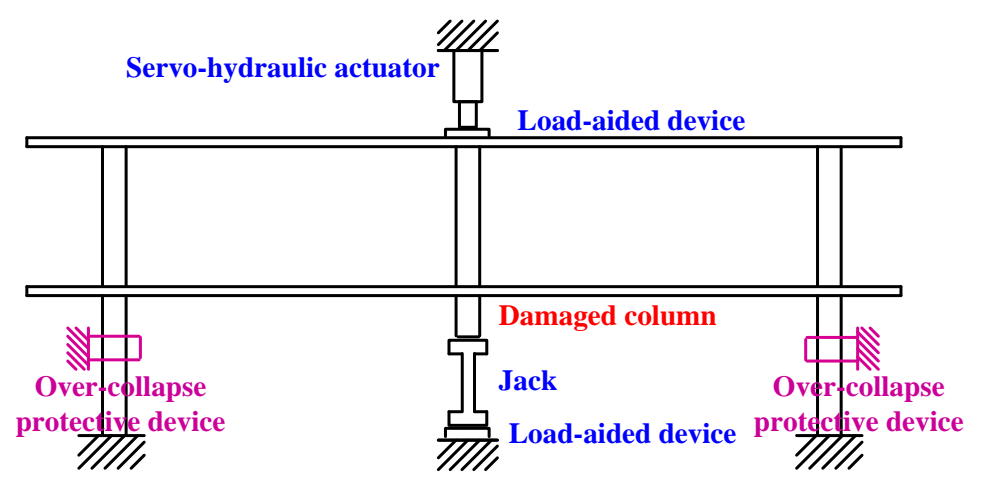

(a) Static test.

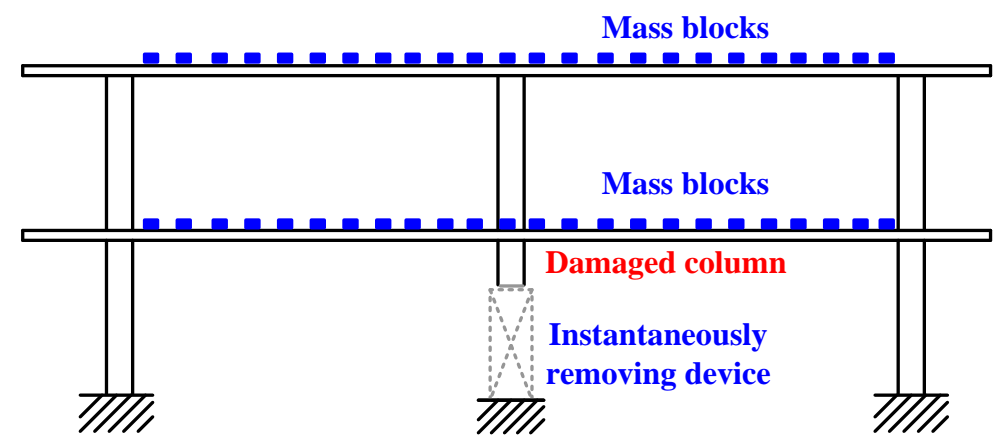

(b) Dynamic test

Fig. (6). The schematic diagram of collapse tests.

State University campus. The demand-capacity ratios of the structural members at different locations were investigated. Sasani et al. [25-28] conducted a series of experiments on real structures by removing structural components. The deformation time history, the internal force distribution and the local damages were tested and analyzed. However, considering the safety and the validity of data, there were no live load in the test, and a few components were removed. After removing the components the entire structures was in small deformation state and the collapse did not occurred. Matthews and Elwood et al. [29] conducted the removing frame column test on a 2-floor RC frame structure by blasting. The redistribution of gravity by dynamic amplifying factor was studied. It was also found that the entire structure was still under linear elastic condition after the frame columns were removed.

\section{NUMERICAL SIMULATION}

When progressive collapse happens, strong nonlinear problems such as large displacement, large rotation, contact and collision between specimens are inevitable. Therefore, it is important to select the appropriate model for analysis to consider these features. Targeting at different objects, various progressive collapse models have been developed. The most representative models are the finite element model and the discrete element model. The finite element model can accurately calculate the mechanical behavior before the failure of the entire structure, but the following condition such as moving and collision between rigid bodies is hardly represented. On the contrary, the discrete element model can perform effectively on this issue but it gives unsatisfying result for the stage before the failure of the structure.

\section{Finite Element Method}

There are three finite element models mainly used for analyzing progressive collapse of building structures, they are the fine model, simplified model and multi-scale model.

The fine model can be established using various elements according to the mechanical behavior of structural members. However, because of its complicated modeling process and large calculation, this method is widely used for specimen or substructures. Hansen and his co-workers [30] established the fine models of concrete and steel frames including the corner model and exterior mid-side model. The progressive collapse resistance of these substructures was analyzed through the transient dynamic and static analysis. Alashker and his co-workers [31] established a fine model for a steelconcrete composite floor system and studied the effects of deck thickness, steel reinforcement, and the number of bolts in the shear tab connection. Qi [32] numerically simulated the progressive collapse and collision of RC slabs by using a fine finite element model. Based on the results, the relation between the progressive collapse resistance of the slabs and the controlling coefficients (such as thickness, reinforcement ratio and reinforcing bar spacing) are concluded. Luccioni and his co-workers [33] established a fine model of a RC structure, studied its progressive collapse including the contact of structural fragments under blast loads.

Although the fine model is close to the actual situation, this method is more time-consuming and laborious. Hence, the simplified model is more preferred in the investigations on the progressive collapse of entire structural systems. Simplified finite element model considers the ultimate mechanical behavior of structures by correcting structural or 
material parameters. Kaewkulchai and Williamson [34] created a beam-column element with multi-linearization and lumped plasticity. A damage index is introduced to consider the degradation of stiffness and strength of structural members of which the failure can be recognized by this index in analysis. When failure occurs, the stiffness of members will be modified and the internal force will be released. Therefore, simplified finite element model with damage index can simulate the actual failure condition during progressive collapse. Grierson, Safi and $\mathrm{Xu}$ [35] used a freedom-degree-releasing technique and an equivalent spring method to simulate the elastic-plastic damage of the structures during progressive collapse. Kim [36] developed a similar model via OpenSees. Since the simplified finite element method with insufficient consideration of the contact situation, Kaewkulchai and Williamson [37] created a simplified finite element model involved with contact condition. Assuming that the failed members against other structural components, the loading speed of the remaining structure can be calculated based on the conservation of momentum. This method can automatically assess the impact effect due to falling failed members on the remaining structure. After combining the bar elements and hinges into the system, Zhang and Liu [38, 39] built a model that could describe the accumulation of large deformation in some extent. Jiao [40] $\mathrm{Ni}$ and Tang [41] developed the simulating methods for the collapse of RC frames. Lu et al. [42] used an element deactivation method to simulate the failure and fracture of structural members during collapse process based on the fiber beam model and layered shell model. Li et al. [43] used instantaneous component-removing method to analyze the progressive collapse of a space grid structure. Du et al. [44] used LS-DYNA to analyze the whole progressive collapse process of a steel frame. $\mathrm{Wu}$ and Huang [45] theoretically analyzed the collision of the slabs based on energy theory, and developed a simplified evaluating method to investigate the impact of floor slabs during structural collapse.

For the multi-scale model, the structural components under complex stress states (e.g. joints) are simulated by the fine model whilst the other parts in the structural systems are represented by the simplified model. In this way, the accuracy of the simulation can be guaranteed and the timeconsuming in computation is greatly reduced. Karnsand and Oughton [46] used this method to simulate the progressive collapse of a high-rise steel frame. Macro model was introduced to describe the geological and material non-linear behavior of the specimens while micro model was used to simulate the contact, failure and material of the connections which are under complex non-linear condition. Talaat and Mosalam [47], Kunnath and Ei-Tawil et al. [48, 49] did similar research as well.

\section{Discrete Element Method}

Discrete element method (DEM) simulates the mechanical behavior of the structure by rigid bodies connected with springs. The internal forces between the rigid bodies are given by the constitutive relations of the springs while the movement of the rigid bodies is determined following the Newton's laws of motion. This method shows great adaptability when dealing with the displacement and contact of rigid bodies. Pekau and Cui [50] used this method to study the progressive collapse of a twelve -storey, threebay precast panel shear wall. Munjiza and his co-workers [51] used combined finite-discrete element method to simulate the collapse of a structure. The comparison between the numerical analysis and the experiment showed that this method can accurately simulate the collapse of the structure while simplified the model establishing and calculating process. Dong Qin [52] and Sun et al. [53] used DEM to study the collapse of RC bridges under the seismic effect. $\mathrm{Gu}$ and Sun [54], Huang [55] used DEM to analyze the collapse of RC frame.

\section{THEORETICAL ANALYSIS}

The theoretically analyses mainly focus on the progressive collapse resistance demand and the robustness assessment for building structures. In the practical design, the progressive collapse resistance demand should be calculated to determine the required capacity of structural members. And the robustness assessment is needed for the engineering optimization design to judge which structure scheme is better or for the scientific researches to recognize which factors (e.g. material and structural parameters) greatly influence the progressive collapse resistance. These two issues should be concerned based on the mechanical and mathematic models in which the behavior of structural systems can be comprehensively considered.

\section{Calculation for Progressive Collapse Resistance Demand}

Progressive collapse is a dynamic response of structures with nonlinear development in material and geometrical properties. The theoretical researches are mainly aiming at the nonlinear dynamic effects on the internal forces and the resistance demand of structures during the collapse process. That is very useful for the simplified design to prevent progressive collapse using the linear or nonlinear static analysis in which the dynamic effect is considered by a nonlinear dynamic amplification factor (DAF).

The dynamic effect can be considered by directly comparing the internal forces and deformations in the dynamic and static analyses. However the simple mathematic expression of the dynamic effect is hardly obtained based on this method, because the dynamic equation for structural progressive collapse is vary complex. Marjanishvili and Agnew [56] found that the dynamic analysis can better describe the progressive collapse of structures via the simulation for a nine-storey steel momentresistant frame structure, and the resistance demand calculated by the linear static method in GSA guideline is not conservative as considered before. Ruth, Marchand and Williamson [57] illustrated that the dynamic amplification factors in GSA and DoD guidelines, which are 2.0, are overconservative while a value of 1.5 might be more accurate to calculate the dynamic response during collapse. Digesh et al.[58] compared the numerical results of demandcapacity ratios (DCR) obtained from the linear and nonlinear static analyses for the progressive collapse of a four- and a ten-storey frame reinforced concrete structures. The results showed that plastic hinges initially yielded at the locations with maximum DCR. The DCR was also studied by Kim 
[59] using the similar method. Buscemi and Marjanishvili [60] established a single degree of freedom (SDOF) model to represent the structural collapse. The nonlinear and dynamic effects were analyzed by applying the dynamic theory on the SDOF method. Based on this method, the relationship between DCR and the structural ductility ratio were discussed. Cai and $\mathrm{Xu}$ et al. [61] analyzed the dynamic effect during the progressive collapse of a cable-stayed bridge by using four methods, and found that the static analysis procedure in which a dynamic amplification factor of 2.0 was applied could well assess the dynamic response of the cable-stayed bridge. Qian and $\mathrm{Hu}$ [62] studied the effect of DCR on the structural deformation during the collapse of a multi-floor steel frame. Wang et al. [63] analyzed the effect of the different structural pattern on the maximum DCR of space steel frames. Feng et al. [64] studied DAF for space truss structures and suggested that a DAF of 2.0 is suitable to predict their nonlinear dynamic behavior. Wang and Liu [65] studied the effect of the failure time of structural members and the material characteristics on the structural dynamic response.

On the other hand, the energy balance equation for structural collapse is much simpler than the dynamic equation. Based on the energy method, a simple equation can be established by which the relationship among collapse load, structural internal force and deformation can be expressed. Sasani and Sagiroglu [66], based on the multidegree-of-freedom (MDOF) and the equivalent SDOF systems for structural collapse, analyzed the influence of structural parameters on the energy dissipation of structures. Tasi $[67,68]$, based on an inelastic SDOF system for ductile structures, established the relationship between nonlinear static and dynamic resistance demands under the equivalent displacement condition and the relationship between nonlinear static and dynamic displacement demands under the equivalent force condition. Lee and his co-workers [69] obtained the simplified resistance curve of steel frame beams by finite element analysis, then they analyzed the energy during the collapse of multi-storey steel frames and proposed a spectrum for collapse analysis. Szyniszewski and Krauthammer [70] analyzed the progressive collapse of steel frame buildings based on an energy flow perspective, indicating that the deformation energy of columns can be used as the stability indicator. Dusenberry and Hamburger [71], Izzuddin et al. [72, 73] established the methods to calculate the dissipating energy of structural systems. Therefore the resistance demand can be assessed based on the balance of the energy dissipation of structures and the gravity potential energy. Xu and Ellingwood [74] proposed a energy based the nonlinear static Pushdown method. In this method, the performance point was found via the iterative calculations for the energy dissipation and the gravitational potential energy. However, the energy dissipation of every structural member in structures and the work done by the unbalanced gravity load should be calculated in this method which leaded to a large workload in the practical design. To end this, based on the energy analysis for a SDOF system, Pujol el al. [75] established a simple relationship between the yield state and the ultimate collapse state of structures by which the progressive collapse demand could be rapidly calculated. $\mathrm{Li}$ and his co-workers [76, 77] established a theoretical framework for analyzing the resistance demand. The relationships between the nonlinear dynamic and linear static progressive collapse resistance demands at structural and elemental levels for RC frame structures were discussed based on the energy conservation principle. It could be used to correct the simplified static calculation in engineering design, approaching the actual nonlinear dynamic calculation.

\section{Assessment Method for Structural Robustness}

Robustness is defined as the ability of a system to resist change without adapting its initial stable configuration. The concept of robustness is widely used in the fields of
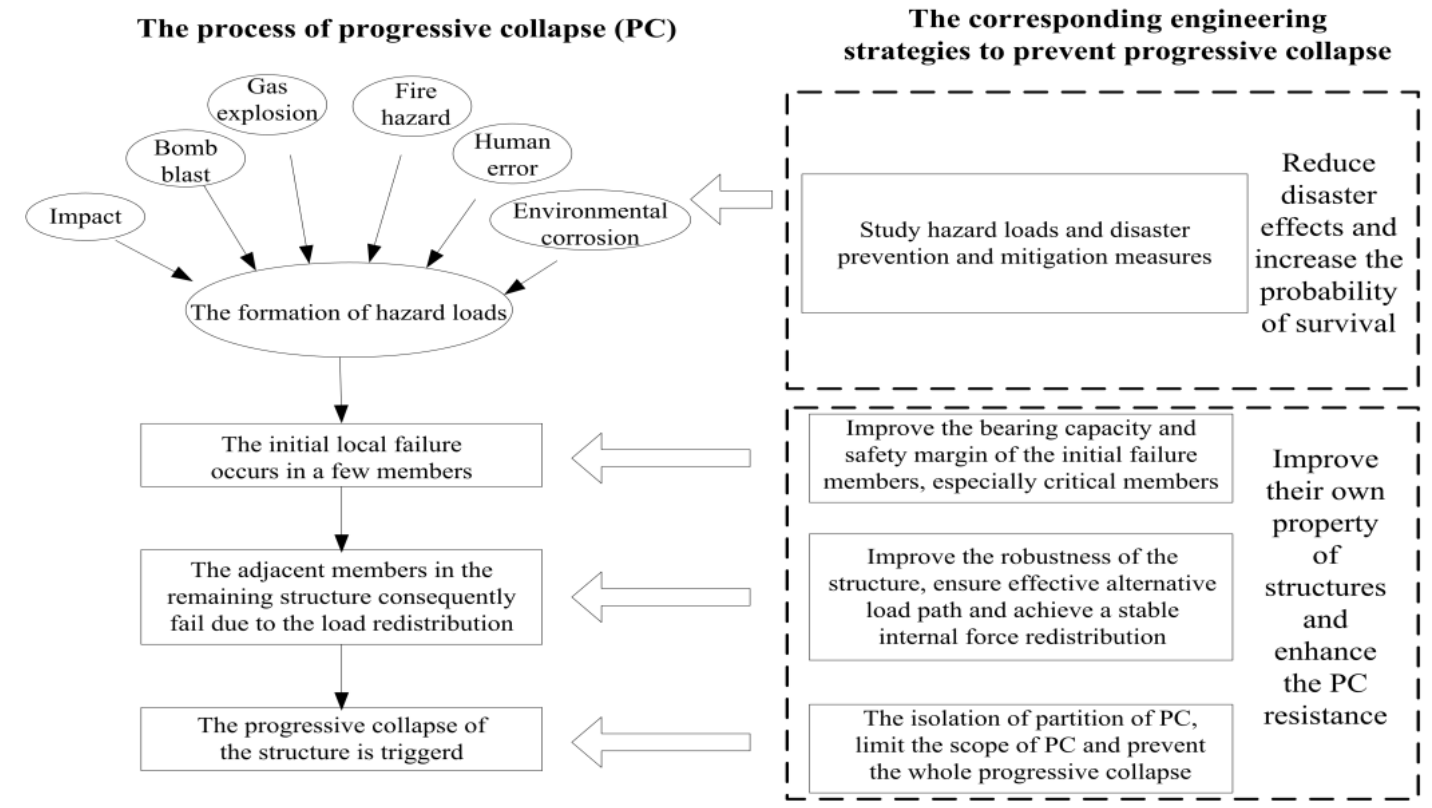

Fig. (7). The process and engineering design measures of structural progressive collapse. 
engineering, nature and society. For civil engineering, the robustness of a structure refers to the structural ability to withstand the local damage due to an accident action. The structural robustness firstly appeared in 1968, when the issue of the progressive collapse of Ronan Point apartment occurred [78]. Many indexed had been proposed to assess robustness based on the comparison of the structural parameters before and after the local failure occurred.

Lind [79] defined the ratio of the collapse probability of the damaged system to that of the undamaged system as an index to assess the structural robustness. Beeby [80] pointed out that the energy dissipating ability could be used as an index for judging the robustness of structural components. Further, the robustness of the whole building can be enhanced by improving the robustness of every single component. Baker and his co-workers [81] suggested a riskbased robustness index that was defined as the ratio of the indirect risk to total risk of structural collapse. Izzuddin [82] used an instantaneous component-removing method to analyze the robustness of a structure. The result showed that the structural robustness was related with the structural failure in the upper floors above the damaged columns. Khandelwala and El-Tawil [83] proposed a robustness assessment based on the Pushdown analysis in which the energy in structural system is calculated dependence with the structural collapse model. Masoero et al. [84] proposed a model that analyze the progressive collapse of 2D frame structures, and found that the progressive collapse resistance can be enhanced via the robustness-based design. Nafday [85] used the structural stiffness matrix to determine the structural robustness. The progressive collapse resistance and the alternative load path in structural systems could be analyzed by this method. Agarwal, Blockley and Woodman [86] proposed a theory of structural vulnerability by analyzing the connectivity of structural form which can be used to assess the structural robustness. Fang and $\mathrm{Li}$ [87] defined the ratio of the failure energy of structural members to the work done by the collapse load as an index for the robustness in which the influence of actual bearing capacity could be considered. Liu [88] defined the ratio of the area influenced by the failure of structural members to the total area as the robustness index by analyzing critical structures. Further, the effect of structural members on the stiffness of structural systems was used to identify the importance of the members which was consequently introduced into the former robustness assessment method [89]. The change of the deformation energy of structural systems before and after failure of structural members was defined as an index to assess the importance of the members by Gao [90] and Zhang [91]. Based on the same methodology, Hu et al. [92] used the structural basic frequency as the index for judging the importance of the structural components. Lv et al. [9394] suggested three indexes based on the load-carrying capacity, reliability and risk respectively to assess the robustness of structures. By using these indexes, they assessed the seismic robustness of RC frame structures designed according to the current codes of China.

\section{The Design Approaches to Prevent Progressive Collapse}

The progressive collapse of building structures includes 4 stages, as shown in Fig. (7): (1) a hazard load acts on a structure; (2) a few members in the structure is damaged; (3) the adjacent members in the remaining structure consequently fail due to the load redistribution; (4) the progressive collapse of the structure is triggered. Progressive collapse can be effectively prevented if the development in any stage is controlled. The corresponding engineering strategies to prevent progressive collapse are proposed according to the four stages. Ellingwood [95], as a pioneer on studying progressive collapse of building structures, proposed three design methods, including an incident controlling method, an indirect design method and a direct design method. The first method was aiming at stage 1, whilst the latter two were aiming at stage 2 and 3 . Accordance with the types of progressive collapse, Starossek [96] suggested a series of strategies toward the progressive collapse resistance during the four stages. Ye and $\mathrm{Lu}$ et al. [97] conducted a similar study based on the same method.

The design methods for progressive collapse of building structures are classified into the two following categories: (1) the incident-dependent progressive collapse design; (2) incident-independent progressive collapse design. The former method is more accurate by relatively complex since the accidental actions should be considered in the modeling and calculation. Besides, there's still no standard procedure for this kind of design. Hence, it is mostly used for the buildings with high safety requirement, such as the design for building structures to prevent blasting action as regulated by UFC3-340-02 [98]. The latter method is simpler which directly design the progressive collapse resistance of structures no regarding the incidental actions.

\section{CONCLUSION}

(1) The majority of the experimental studies used the static loading pattern without considering the dynamic effect in the actual collapse process. Ignoring the effect may misunderstand the collapse mechanism of building structures due to the material properties (e.g. ultimate strength and fracture strain) and the internal force development in structural members under dynamic state are quit different with that under static loading. The experimental technique for the dynamic collapse test should be investigated to promote the researches on this issue.

(2) The numerical methods for progressive collapse have been introduced in this paper. However, most of them could be only applied on simple structures, such as regular steel or concrete frame buildings. The numerical model with high performance for the actual complex structures is still lacking which is widely required in the practical design. The multi-scale numerical simulation is considered as an effective method in which the parts of structures under complex stress state could be simulated by the accurate but computation-consuming models whilst the other parts in the structures may be simulated by the macro models with high efficiency.

(3) The nonlinear dynamic effect in the simple structures (i.e. frame structures) is investigated based on the dynamic and energy theories. However, the nonlinear dynamic effect for the other type structures is still needed. The existing methods to assess the structural 
robustness are mainly used in researches and the application of them in the practical design is rare due to the obscure physical and mathematic signification and the complex calculation. The engineering-friendly assessment is required to improve the progressive collapse design.

\section{CONFLICT OF INTEREST}

The authors confirm that this article content has no conflicts of interest.

\section{ACKNOWLEDGEMENTS}

Declared None.

\section{REFERENCES}

[1] B.R. Ellingwood, "Mitigating risk from abnormal loads and progressive collapse," Journal of Performance of Constructed Facilities, vol.20, no.4, pp.315-323, Nov. 2006.

[2] H. Griffiths, A. Pugsley, and O. Saunders. "Report of the inquiry into the collapse of flats at Ronan Point, canning town." Tech. Report, London: Her Majesty's Stationary Office, 1968.

[3] W.G. Corley, P.F. Mlakear Sr., M.A. Sosen, and C.H. Thornton $\mathrm{CH}$, "The Oklahoma city bombing: summary and recommendations for multihazard mitigation," Journal of Performance of Constructed Facilities, vol.12, no.3, pp.100-112, Aug. 1998.

[4] NIST, "Final report on the collapse of the world trade center towers," Tech. Report, Gaithersbuig: National Institute of Standards and Technology, 2005.

[5] B. Crowder, D.J. Stevens, and K.A. Marchand, "Design of buildings to resist progressive collapse," Virginia Society of Professional Engineers Tidewater Chapter \& DoD Security Engineering Working Group, Short course proceedings of Security Engineering Workshop, 2004.

[6] China. Ministry of Housing and Urban-Rural Development of the People's Republic of China. "Code for design of concrete structures GB50010-2010," Peking: Ministry of Housing and Urban-Rural Development of the People's Republic of China, 2010 .

[7] China. Ministry of Housing and Urban-Rural Development of the People's Republic of China. "Technical specification for concrete structure of tall building JGJ3-2010," Peking: Ministry of Housing and Urban-Rural Development of the People's Republic of China, 2010.

[8] A.A. Abolhassan, E.A. Madsen and C. Noble, "Use of catenary cables to prevent progressive collapse of buildings," Tech. Report UCB/CEE-Steel-2001/02. Berkely: University of California. Department of Civil and Environmental Engineering, 2002.

[9] M. Sasani and J. Kropelnicki, "Progressive collapse analysis of an RC structure," The Structural Design of Tall and Special Buildings, vol.17, no.4, pp.757-771, July 2007.

[10] K. Qian and B. Li, "Experimental and analytical assessment on rc interior beam-column subassemblages for progressive collapse," Journal of Performance of Constructed Facilities, vol.26, no.5, pp.576-589, Oct. 2012.

[11] K. Qian and B. Li, "Dynamic performance of RC beam-column substructures under the scenario of the loss of a corner columnexperimental results," Engineering Structures, vol.42, pp.154-167, May 2012.

[12] F. Sadek, J. A Main, H.S. Lew and Y.H. Bao, "Testing and analysis of steel and concrete beam-column assemblies under a column removal scenario," Journal of Structural Engineering, vol.137, no.9, pp.881-892, Sep.2011.
[13] Y.P. Su, Y. Tian and X.S. Song, "Progressive collapse resistance of axially-restrained frame beams," ACI Structural Journal. Vol.106, no.5, pp.600-607, Sep.2009.

[14] W.J. Yi, Q.F. He, Y. Xiao and S.K. Kunnath, "Experimental study on progressive collapse-resistant behavior of reinforced concrete frame structures," ACI Structural Journal, vol.105, no.4, pp.433439, Aug. 2008

[15] S.L. Yap and B. Li, "Experimental investigation of reinforced concrete exterior beam-column subassemblages for progressive collapse," ACI Structural Journal, vol.108, no.5, pp.542-552, Oct. 2011.

[16] D. Mitchell and W.D. Cook, "Preventing progressive collapse of slab structures," Journal of Structural Engineering, vol.110, no.7, pp.1513-1532, July 1984.

[17] M. Zineddin and T. Krauthammer, "Dynamic response and behavior of reinforced concrete slabs under impact loading," International Journal of Impact Engineering, vol.34, no.9, pp.1517-1534, Sep.2007.

[18] F.Z. Zhang and W.J. YI, "Collapse experiment research and analysis of a RC flat plate," Journal of Hunan University (Natural Sciences), vol.37, no.4, pp.1-5, Apr. 2010.

[19] Q.H. Huang, "Study on spatial collapse responses of reinforced concrete frame structures under earthquake," Ph.D. thesis, Tong ji University, China, 2006.

[20] W.J. YI, Q.F. He and Y. Xiao, "Collapse performance of RC frame structure," Journal of Building Structures, vol.28, no.5, pp.104109, Oct. 2007.

[21] J.G. Xiong, Z.Q. Wu, Y.N. He X.X. Nie and C.F. Xia, "Experimental research on progressive collapse performance of RC spatial frame structures," Journal of Nanchang University (Engineering\&Technology), vol.34, no.3, pp.229-232, Sep. 2012.

[22] X.Z. Lu, L.P. Ye, P. Pan, Z.Z Zhao, X.D. Ji and J.R. Qian, "Pseudo-static collapse experiments and numerical prediction competition of RC frame structure I: RC frame experiment," Building Structure, vol.42, no.11, pp.19-22, 26, Nov. 2012.

[23] X.Z. Lu, L.P. Ye, P. Pan, D.Y. Tang and J.R. Qian, "Pseudo-static collapse experiments and numerical prediction competition of RC frame structure II: key elements experiment," Building Structure, vol.42, no.11, pp.23-26, Nov.2012.

[24] B.I. Song and H. Sezen, "Evaluation of an existing steel frame building against progressive collapse," In: Structures Congress 2009, pp.1878-1885.

[25] M. Sasani, M. Bazan and S.Sagiroglu, "Experimental and analytical progressive collapse evaluation of actual reinforced concrete structure," ACI Structural Journal, vol.104, no.6, pp.731739, Nov. 2007.

[26] M. Sasani and S. Sagiroglu, "Progressive Collapse Resistance of Hotel San Diego," Journal of Structural Engineering, vol.134, no.3, pp.478-488, Mar. 2008.

[27] M. Sasani, A. Kazemi, S. Sagiroglu and S. Forest, "Progressive collapse resistance of an actual 11-story structure subjected to severe initial damage," Journal of Structural Engineering, vol.137, no.9, pp.893-902, Sep. 2011.

[28] M. Sasani and S. Sagiroglu, "Gravity load redistribution and progressive collapse resistance of 20 -story reinforced concrete structure following loss of interior column," ACI Structural Journal, vol.107, no.6, pp.636-644, Nov. 2010.

[29] T. Matthews, K.J. Elwood and S.J. Hwang, "Explosive testing to evaluate dynamic amplification during gravity load redistribution for reinforced concrete frames," In: Structures Congress 2007: Structural Engineering Research Frontiers, 2007.

[30] E. Hansen, F. Wong and D. Lawver, "Development of an analytical database to support a fast running progressive collapse assessment tool," In: Proceeding of ASCE/SEI, 2005. 
[31] Y. Alashker, S. El-Tawil and F. Sadek, "Progressive collapse resistance of steel-concrete composite floors," Journal of Structural Engineering, vol.136, no.10, pp.1187-1196, Oct. 2010.

[32] H.T. Qi and Q.L. LI, "Research on crush of reinforced slabs in progressive collapse," Building Structure, vol.40 (S2), pp.358-364, June 2010.

[33] Luccioni B M, Ambrosini R D, Danesi R F, “Analysis of building collapse under blast loads," Engineering Structures, vol.26, no.1, pp.63-71,2004.

[34] G. Kaewkulchai and E.B. Williamson, "Beam element formulation and solution procedure for dynamic progressive collapse analysis," Computers and Structures, vol.82, no.7-8, pp.639-651, Dec.2004.

[35] D.E. Grierson, M. Safi, L. Xu and Y.X. Liu, "Simplified methods for progressive-collapse analysis of buildings," In: Structures Congress 2005, pp.1-8.

[36] H.S. Kim, J. Kim and D.W. An, "Development of integrated system for progressive collapse analysis of building structures considering dynamic effects," Advances in Engineering Software, vol.40, no.1, pp.1-8, May 2008.

[37] G. Kaewkulchai and E.B. Williamson, "Modeling the impact of failed members for progressive collapse analysis of frame structures," Journal of Performance of Constructed Facilities, vol.20, no.4, pp.375-383, Nov. 2006.

[38] L.M. Zhang, "The study on the mechanism of structural collapse under disaster loading," Ph.D. thesis, Tsinghua University: China, 2000.

[39] L.M. Zhang and X.L. Liu, "Forward research of collapse analysis of reinforced concrete structures," Earthquake Engineering and Engineering Vibration, vol.23, no.3, pp.47-52, June 2003.

[40] S.J. Jiao, Q.M. Feng and C.W. FU, "Simulation method for earthquake damage to RC frames," Earthquake Engineering and Engineering Vibration, vol.22, no.2, pp.54-59, Apr. 2002.

[41] Q. Ni and J.X. Tang, "On multimedia simulation system for RC frame structures during earthquake collapse," Engineering Mechanics, vol.17, no.4, pp.56-60, Aug. 2000.

[42] X.Z. Lu, X.C. Lin, L.P. Ye, Y. Li and D.Y. Tang, "Numerical models for earthquake induced progressive collapse of high-rise buildings," Engineering Mechanics, vol.27, no.11, pp. 64-70, Nov. 2010 .

[43] Y. Ding, J.G. Ge and Z.X. Li, "Instantaneous component-removing method for analysis of progressive collapse of space grid structure," Journal of Tianjin University, vol.44, no.6, pp. 471-476, June 2011.

[44] X.L. Du and L.Shi, "A study on progressive collapse of steel-frame building under explosion," Journal of Beijing University of Technology, vol.39, no.7, pp.986-993, July 2013.

[45] B. Wu and S.X. Huang, "A Simplified evaluating method for impacting of floor slabs during structural collapse," Engineering Mechanics, vol.30, no.3, pp. 306-314, Mar. 2013.

[46] J.E. Karns and D.L. Houghton, "Macro and micro nonlinear analysis methods to assess progressive collapse potential in highrise steel frame buildings as a function of beam-to-column connection behavior," In: Proceedings of the $74^{\text {th }}$ Shock \& Vibration Symposium, 2003, pp. U-031.

[47] M. Talaat and K.M. Mosalam, "Towards Modeling Progressive Collapse in Reinforced Concrete Buildings," In: Proceedings of the 2007 Structures Congress, 2007.

[48] Y. Bao, S.K. Kunnath, S. El-Tawil and H.S. Lew, "Macromodelbased simulation of progressive collapse: RC frame structures," Journal of Structural Engineering, vol.134, no.7, pp.1079-1091, July 2008.

[49] K. Khandelwal, S.K. Kunnath and S. El-Tawil, "Macromodelbased simulation of progressive collapse: Steel frame structures,"
Journal of Structural Engineering, vol.134, no.7, pp.1070-1078, July 2008.

[50] O.A. Pekau and Y. Cui, "Progressive collapse simulation of precast panel shear walls during earthquakes," Computers and Structures, vol.84, no.5-6, pp.400-412, Nov. 2005.

[51] Munjiza, T. Bangash and N.W.M. John, "The combined finitediscrete element method for structural failure and collapse," Engineering Fracture Mechanics, vol.71, no.4, pp.469-483, Nov. 2004.

[52] D. Qin, "Reinforced concrete bridge pier lateral earthquake damage and the collapse of the computer simulation," Ph.D. thesis, Tong ji University, China, 2000.

[53] L.M. Sun, C. Zhou, D. Qin and L.C. Fan, “Application of extended distinct element method with lattice model to collapse analysis of RC bridge," Earthquake Engineering and Structural Dynamics, vol.32, pp.1217-1236, Dec. 2003.

[54] X.L. Gu and F.F. Sun, Computer Simulation of Concrete Structures. Routledge: Shang Hai, 2002.

[55] Q.H. Huang, "Study on spatial collapse responses of reinforced concrete frame structures under earthquake," Ph.D. thesis, Tong ji University, China, 2006.

[56] S. Marjanishvili and E. Agnew, "Comparison of various procedures for progressive collapse analysis," Journal of Performance of Constructed Facilities, vol.20, no.4, pp.365-374, Nov. 2006.

[57] P. Ruth, S.M. Marchand and E.B. Williamson, "Static equivalency in progressive collapse alternate path analysis: reducing conservatism while retaining structural integrity," Journal of Performance of Constructed Facilities, vol.20, no.4, pp.349-364, Nov. 2006.

[58] D.J. Digesh, V. P. Paresh and J.T. Saumil, "Linear and nonlinear static analysis for assessment of progressive collapse potential of multistoried building," In: Structures Congress 2010, pp.35783589.

[59] K. Jinkoo and K. Taewan, "Assessment of progressive collapseresisting capacity of steel moment frames," Journal of Constructional Steel Research, vol.65, no.1, pp.169-179, Mar. 2008.

[60] N. Buscemi and S. Marjanishvili, "SDOF model for progressive collapse analysis," In: Proceedings of the 2005 Structures Congress and the 2005 Forensic Engineering Symposium, Metropolis \& Beyond, 2005.

[61] J.G. Cai, Y.X. Xu, L.p. Zhuang, J. Feng and J. Zhang, "Comparison of various procedures for progressive collapse analysis of cable-stayed bridges," Journal of Zhejiang UniversitySCIENCE A (Applied Physics \& Engineering), vol.13, no.5, pp.323-334, Apr. 2012.

[62] J.R. Qian and X.B. Hu, "Dynamic effect analysis of progressive collapse of multistory steel frames," Earthquake Engineering and Engineering Vibration, vol.28, no.2, pp.8-14, Apr. 2008.

[63] T.C. Wang, J. Kang and Z.P. LI, "Analysis of progressive collapse resistance of space frames," Engineering Mechanics, vol. 28(S2), pp.161-165, Dec. 2011.

[64] F. Feng, J.G. Cai, J. Feng, F.L. Wang and J. Zhang, "Load dynamical increasement factor of space truss," Spatial Structures, vol.17, no.1, pp.28-32, Mar. 2011.

[65] T.C. Wang and C.Q. Liu, "Analysis of structural dynamic response characteristics in progressive collapse," Journal of Vibration and Shock, vol.29, no.5, pp.69-73, 2010.

[66] M. Sasani and S. Sagiroglu, "Progressive collapse of reinforced concrete structures: a multihazard perspective," ACI Structural Journal, vol.105, no. 1, pp. 96-103, Jan. 2008.

[67] M.H. Tsai, "An analytical methodology for the dynamic amplification factor in progressive collapse evaluation of building 
structures," Mechanics Research Communications, vol.37, no.1, pp.61-66, Nov. 2010.

[68] M.H. Tsai and B.H. Lin, "Investigation of progressive collapse resistance and inelastic response for an earthquake-resistant RC building subjected to column failure," Engineering Structures, vol.30, no.12, pp.3619-3628, Dec. 2008.

[69] C.H. Lee, S. Kim, K.H. Han and K. Lee, "Simplified nonlinear progressive collapse analysis of welded steel moment frames," Journal of Constructional Steel Research, vol.65, no.5, pp.11301137, Oct. 2008.

[70] S. Szyniszewski and T. Krauthammer, "Energy flow in progressive collapse of steel framed buildings," Engineering Structures, vol.42, no.1, pp.142-153, May 2012.

[71] D.O. Dusenberry and R.O. Hamburger, "Practical means for energy-based analyses of disproportionate collapse potential," Journal of Performance of Constructed Facilities, vol.20, no.4, pp.336-348, Nov. 2006.

[72] B.A. Izzuddin, A.G. Vlassis, A.Y. Elghazouli and D.A. Nethercot, "Progressive collapse of multi-storey buildings due to sudden column loss-Part I: Simplified assessment framework," Engineering Structures, vol.30, no.5, pp.1308-1318, Sep. 2007.

[73] A.G. Vlassis, B.A. Izzuddin, A.Y. Elghazouli and D.A. Nethercot, "Progressive collapse of multi-storey buildings due to sudden column loss-Part II: Application," Engineering Structure, vol.30, no.5, pp.1424-1438, Sep. 2007.

[74] G.Q. Xu and B. R. Ellingwood, "An energy-based partial pushdown analysis procedure for assessment of disproportionate collapse potential," Journal of Constructional Steel Research, vol.67, no.3, pp.547-555, Sep. 2010.

[75] S. Pujol and J.P. Smith-Pardo, "A new perspective on the effects of abrupt column removal," Engineering Structures, vol.31, no.4, pp.869-874, Jan. 2009.

[76] Y. Li, L.P. Ye and X.Z. Lu, "Progressive collapse resistance demand of RC frame structures based on energy method I: beam mechanism," Journal of Building Structures, vol.32, no.11, pp.1-8, Nov. 2011.

[77] Y. Li, L.P. Ye and X.Z. Lu, "Progressive collapse resistance demand of RC frame structures based on energy method II: catenary mechanism," Journal of Building Structures, vol.32, no.11, pp.9-16, Nov. 2011.

[78] Z.X. Fang and H.Q. Li, "Safety and robustness of structures from the viewpoint of energy," Journal of Building Structures (Supplementary Issue), vol.S1, pp.269-273, Apr. 2007.

[79] N.C. Lind, "A measure of vulnerability and damage tolerance," Reliability Engineering and System Safety, vol.48, no.1, pp.1-6, Dec.1994.

[80] A.W. Beeby, "Safety of structures, and a new approach to robustness," The Structural Engineer, IStructE, vol.77, no.4, pp.1621, Feb. 1999.

[81] J.W. Baker, M. Schubert and M.H. Faber, "On the assessment of robustness," Structural Safety, vol.30, no.3, pp.253-267, Jan. 2007.
[82] B.A. Izzuddin, "Mitigation of Progressive Collapse in Multi-Storey Buildings," Advances in Structural Engineering, vol.15, no.9, pp.1505-1520, Oct. 2012.

[83] K. Khandelwala and S. El-Tawil, "Pushdown resistance as a measure of robustness in progressive collapse analysis," Engineering Structures, vol.33, no.9, pp. 2653-2661, June 2011.

[84] E. Masoero, P. Daro and B.M. Chiaia, "Progressive collapse of 2D framed structures: An analytical model," Engineering Structures, vol.54, no.9, pp.94-102, Mar. 2013..

[85] A.W. Nafday, "System safety performance metrics for skeletal structures," Journal of Structure Engineering, vol.134, no.3, pp.499-504, Mar. 2008.

[86] J. Agarwal, D.Blockley and N. Woodman, "Vulnerability of structural systems," Structural Safety, vol.25, no.3, pp.263-286, Jan. 2003.

[87] Z.X. Fang and H.Q. Li, "Structural robustness and risk mitigation," Engineering Mechanics, vol.24 (Sup.I), pp.79-82, Apr. 2007.

[88] C.M. Liu and X.L. Liu, "Study on the comprehensive assessment method of structural reliability," Sichuan Building Science, vol.30, no.4, pp.46-48, Dec. 2004

[89] C.M. Liu and X.L. Liu, "Stiffness-based evaluation of component importance and Its relationship with redundancy," Journal of Shang Hai Jiao Tong University, vol.39, no.5, pp.746-750, May. 2005.

[90] Y. Gao and X.L. Liu, "Importance coefficients of components in evaluation of structure robustness," Chinese Journal of Rock Mechanics and Engineering, vol.27, no.12, pp.2575-2594, Dec. 2008.

[91] L.M. Zhang and X.L. Liu, "Network of energy transfer in frame structures and its preliminary application," China Civil Engineering Journal, vol.40, no.3, pp.45-49, Mar. 2007.

[92] X.B. Hu, "Study on the performance of progressive collapse of the new polyhedron space frame structure," Ph.D. thesis, Tsinghua University, China, 2000.

[93] D.G. Lv, S.S. Cui, Y.J. Li and G.Y. Wang, "Robustness analysis for progressive collapse of structures using ALP-Based pushover analysis approach," Journal of Building Structures (Supplementary Issue 2), vol. (Sup. I), pp.112-118, Oct. 2009.

[94] D.G. Lv, P.Y. Song, S.S. Cui and M.X. Wang, "Structural robustness and its assessment indicators," Journal of Building Structures, vol.32, no.11, pp.44-54, Nov. 2011.

[95] B.R. Ellingwood and E.V. Leyendecker, "Approaches for design against progressive collapse," Journal of Structural Division (ASCE), vol.104, no.3, pp.413-423, Mar. 1978.

[96] U. Starossek, "Typology of progressive collapse," Engineering Structures, vol.29, no.9, pp.2302-2307, Sep. 2007.

[97] L.P. Ye, X.Z. Lu, Y. Li, Y. Liang and Y.F. Ma, "Design method on the progressive-collapse-resistance of RC frames," Building Structure, vol.40, no.2, pp.1-7, Feb. 2010.

[98] USA. Department of Defense. "UFC3-340-02. Structures to resist the effects of accidental explosions," Washington, D.C: Department of Defense, 2008. 